\title{
Critical observations on the statistical process control implementation in the UK food industry: a survey
}

\begin{abstract}
Purpose: Statistical process control (SPC) is widely applied for control and improve processes in manufacturing, but very few studies have reported on the successful application of SPC in the food industry, in particular. The purpose of this paper is to critically assess the status of SPC in the UK food manufacturing industry and to suggest future research avenues. Design/methodology/approach: A research project was carried out in the UK food manufacturing sector through questionnaires. The results of the study were analysed using descriptive statistics and statistical tests to be applied in the hypothesis testing. Findings: Findings revealed that 45 per cent of the respondents are SPC users and $x^{-}-R_{\text {and }}{ }^{-}-\mathrm{S}$ charts are the most commonly applied SPC charts in this industry. It was determined that top management commitment is the most critical factor, while lack of SPC training is the most alarming challenge, and lack of awareness of SPC and its benefits are the main reasons for the food companies not implementing SPC. Research limitations/implications: The study considered only the food manufacturing companies. Future research could be addressed toward the food service and food supply chain. Practical implications: The paper provides information to food companies in the UK on most common practiced and important quality tools, SPC charts and critical success factors in the food industry. Moreover, the most challenging factors of SPC implementation in the food industry are presented. Originality/value: This study depicted the current state of SPC practices in the food industry and the process performance in SPC and non-SPC companies is compared.
\end{abstract}

Keyword: Critical success factors; Continuous improvement; Food industry; Statistical process control; Quality control 